\title{
DESIGN, SYNTHESIS AND BIOLOGICAL SCREENING OF AMINOACETYLENIC TETRAHYDROPHTHALIMIDE ANALOGUES AS NOVEL CYCLOOXYGENASE (COX) INHIBITORS
}

\author{
AHMED BASIM ${ }^{1}$, ZUHAIR A. MUHI-ELDEEN ${ }^{1} \boxminus$, ELHAM N. AL-KAI SSI ${ }^{2}$,GHADEER SUAIFAN ${ }^{3}$, \\ MOHAMMAD A. GHATTAS ${ }^{4}$, TAWFEEQ ARAFAT ${ }^{1}$, IBRAHIM S. AL-ADHAM ${ }^{2}$
}

1Department of Medicinal Chemistry and Pharmacognosy, Faculty of Pharmacy, University of Petra, Amman, Jordan, ${ }^{2}$ Department of Pharmaceutics and Pharmaceutical Technology, Faculty of Pharmacy, University of Petra, Amman, Jordan, ${ }^{3}$ Department of Medicinal Chemistry, Faculty of Pharmacy, Jordan University, ${ }^{4}$ College of Pharmacy, Al Ain University of Science and Technology, Al Ain, United Arab Emirates Email: zeldeen@uop.edu.jo

Received: 03 Oct 2016 Revised and Accepted: 21 Dec 2016

\begin{abstract}
Objective: To design and synthesise a new amino acetylenic tetrahydro phthalimide derivative and investigate their selective inhibitory activity to COXs.

Methods: Aminoacetylenic tetrahydro phthalimide derivatives were synthesised by alkylation of tetrahydro phthalimide with propargyl bromide afforded 2-(prop-2-yn-1-yl)-2,3,3a,4,7,7a-hexahydro-1H-isoindole-1,3-dione. The alkylated tetrahydro phthalimide was subjected to Mannich reaction afforded the desired amino acetylenic tetra phthalimide derivatives (AZ 1-6). The elemental analysis was indicated by the EuroEA elemental analyzer and biological characterization was via IR, ${ }^{1} \mathrm{H}-\mathrm{NMR},{ }^{13} \mathrm{C}-\mathrm{NMR}$, DSC was determined with the aid of Bruker FT-IR and Varian 300 MHz spectrometer and DMSO- $\mathrm{d}_{6}$ as a solvent, molecular docking was done using the Autodock Tool software (version 4.2). ChemBioDraw was used in the drawing of our schemes.

Results: The IR, ${ }^{1} \mathrm{H}-\mathrm{NMR},{ }^{13} \mathrm{C}-\mathrm{NMR}$, DSC and elemental analysis were consistent with the assigned structures. The designers of the compounds as COXs inhibitor activity were based on the nationalisation of the important criteria that provide effective inhibitory binding with COXs-receptor. The results indicated that the synthesised compounds (AZ1-6) showed a close similarity in the binding affinity to both COXs and may be more specific to COX-1. AZ-5 showed the highest \% of inhibition for COX-1 even better than aspirin. Which may suggest that the aryl group is required for COX-2
\end{abstract} inhibition.

Conclusion: For the first time, we indicate the requirement of aromaticity in COX-2 structural inhibitory activity.

Keywords: Aminoacetylenic, Tetrahydrophthalimide, Molecular modelling, Cyclooxygenase inhibitors, Anti-inflammatory

(c) 2016 The Authors. Published by Innovare Academic Sciences Pvt Ltd. This is an open access article under the CC BY license (http://creativecommons.org/licenses/by/4. 0/) DOI: http://dx.doi.org/10.22159/ijpps.2017v9i2.15511

\section{INTRODUCTION}

Nonsteroidal anti-inflammatory drugs (NSAIDs) were widely used to treat acute and/or chronic inflammation due to their ability to relief symptomatic pain $[1,2]$. Conventional NSAIDs are non-selective cyclooxygenases (COX) enzyme inhibitors; they are involved in the biosynthesis of prostaglandin (PGs) from arachidonic acid [3-5]. Two mammalian COX isoforms, COX-1 and COX-2, were identified [3-5]. Constitutive COX-1 which has a housekeeping functions; including gastroprotective and kidney function, regulation of PGs, whereas COX-2 is induced in inflammatory cells and generate PGs that help mediate the inflammatory response. Classical NSAIDs such as aspirin and ibuprofen are non-selective COX inhibitors, which cause a gastric failures like bleeding and ulcer [6,7]. On the other hand, celecoxib, rofecoxib (Vioxx), and valdecoxib are selective COX2 inhibitors, which exhibit anti-inflammatory and analgesic activity with markedly less gastrointestinal (GI) toxicity.

However, rofecoxib was later withdrawn due to the increased cardiovascular risk in patients with heart disease as these patients were more prone to myocardial infarction. This may be attributed to $\mathrm{TxA}_{2} / \mathrm{PGI}_{2}$ imbalance created by selective COX-2 $[8,9]$.

To overcome and minimise COX inhibitors side effects, it was imperative to design and synthesis conformational constrained selective COX inhibitors. Based on our previous works associated with 2-[4-(t-amino-1-yl) but-2-yn-1-yl] isoindoline-1,3-dione, that exerted anti-inflammatory activity with non-selective to COXs. This study was aimed to design and synthesise a rigid but non-flexible structure is lacking aromaticity as amino acetylenic tetrahydro phthalimide. This series may show a selective COX-1 inhibitor activity.

\section{MATERIALS AND METHODS}

\section{A-Experimental}

Chemicals

The following chemicals and materials were used: cis-1,2,3,6 tetrahydro phthalimide 96\% (Sigma-Aldrich, St. Louis, USA), propargyl bromide (Sigma-Aldrich, St. Louis, USA), piperidine 99\% reagent plus (Sigma-Aldrich, St. Louis, USA), 2-methylpipera 99\% (alpha Aesar), 2,6-dimethyleneimine 98\% (Sigma-Aldrich, St. Louis, USA), N-methyl piper a 99\% (Sigma-Aldrich, St. Louis, USA), hexamethylenediamine 98\% (Sigma-Aldrich, St. Louis, USA), ethanol (Giant and chemical company), 1,4-dioxan (Full time Chemicals, Anqing, China), chloroform (BDH chemicals, Pennsylvania, USA), paraformaldehyde (BDH chemicals, Pennsylvania, USA), cuprous chloride (BDH chemicals, Pennsylvania, USA), colorimetric COX (ovine/human) inhibitor screening assay Kit (No. 560131, Cayman, USA).

\section{Chemistry}

Melting points were determined by using a Gallen Kamp melting point apparatus. DSC Differential Scanning Colorimetry using Mettler Toledo DSC1 Stare system, Switzerland. Infrared spectra (IR) using FTIR Bruker.

${ }^{1} \mathrm{H}$ and ${ }^{13} \mathrm{C}$-NMR were acquired with the aid of Varian $300 \mathrm{MHz}$ spectrometer and DMSO- $\mathrm{d}_{6}$ as a solvent, and TMS as standard. The analysis was indicated by EuroEA elemental analyser. The result obtained had a maximum deviation of 3.6 from the theoretical value, which is considered within the acceptable variation range in results $( \pm 4.4 \%)$. This variation range is set according to the accuracy of EuroEA elemental analyser device in the faculty of Pharmacy, 
University of Jordan, Amman, Jordan. ChemBioDraw (Massachusetts, U. S. A.) was used in the drawing of our schemes.

Synthesis of 2-(prop-2-yn-1-yl)-2,3,3a,4,7,7a-hexahydro-1Hisoindole-1,3-dione (AZ-0)

Propargyl bromide in $10 \mathrm{ml}$ actonitril was added to a mixture of cis1,2,3,6-tetrahydrophthalimide ( $2 \mathrm{~g}$ ) and potassium carbonate $\mathrm{K}_{2} \mathrm{CO}_{3}$ $(2.18 \mathrm{~g}$ ), in $20 \mathrm{ml}$ actonitril, refluxed stirred for $80 \mathrm{~min}$ after $80 \mathrm{~min}$, cooled and filtered. The evaporated residue, in $\mathrm{CHCL}_{3}(30 \mathrm{ml})$ was washed with water $(20 \mathrm{ml})$. Drying, evaporation and chromategraphy afforded the desired AZ compound as white powder: IR vmax 3300 (acetylenic C-H stretch), 2150 (C-C triple bond stretch), 1700 (C=0 stretch), 1600 (Ar C=C stretch), $1200 \mathrm{~cm}^{-1}$ (N-C stretch). NMR $\delta_{\mathrm{H}}\left((\mathrm{CD} 3) 2 \mathrm{SO}: \delta_{\mathrm{H}} 5.90(\mathrm{~s}, 2 \mathrm{H}, \mathrm{AH}), 3.6(\mathrm{~s}, \mathrm{H}), 3.15(\mathrm{~s}, \mathrm{H})\right.$. Anal. Calcd, $\left(\mathrm{C}_{11} \mathrm{H}_{11} \mathrm{~N}_{1} \mathrm{O}_{2}\right): \mathrm{C}, 66.2 \%$; $\mathrm{H}, 5.8 \%$; N, $8.3 \%$. Found: $\mathrm{C}, 64.98 \%$; $\mathrm{H}$, $6.0 \% ; \mathrm{N}, 8.1 \%$.

\section{Synthesis of amino acetylenic compounds (AZ 1-6)}

A mixture of 2-(prop-2-yn-1-yl)-2,3,3a,4,7,7a-hexahydro-1Hisoindole-1,3-dione $(2 \mathrm{~g})$, paraformaldehyde $(0.5 \mathrm{~g})$, cyclic amines (around $0.01 \mathrm{~mol}$ ) and cuprous chloride catalytic amount $(0.03 \mathrm{~g})$, in peroxide-free dioxane $35 \mathrm{ml}$ was refluxed for $1 \mathrm{~h}$. filtered and evaporated under reduced pressure afforded compounds (AZ 1-6).

Synthesis of 2-[4-(2, 6-dimethylpiperidine-1-yl) but-2-yn-1-yl]2,3,3a,4,7,7a-hexahydro-1H-isoindole-1,3-dione (AZ-2)

The titled compound was prepared following the general procedure for synthesis of aminoacetylenic compounds 1-6, yielded $3 \mathrm{~g}$ (95.59\%). IR: 2910 (C-H stretch). 2830 (C-H stretch), 1700 (Ar C=0 stretch), 1312 (Ar C-N stretch). ${ }^{1} \mathrm{H}-\mathrm{NMR}$ (DMSO-d $\mathrm{d}_{6}$ ) $\delta, 5.83$ (s, $2 \mathrm{H}$, $\mathrm{ArH}$ ), 4.12 (s, $\mathrm{H}, \mathrm{CH}_{2}-\mathrm{C}$ ), 3.18, 3.45 (d, 2H, C-CH $-\mathrm{N}$ ), 1.55, (m, various protons of cyclic amine). Anal. Calcd, $\left(\mathrm{C}_{19} \mathrm{H}_{26} \mathrm{~N}_{2}\right): \mathrm{C}, 71.10 \%$; $\mathrm{H}$, 8.89\%; N, 8.89\%. Found: C, 71.05; H, 8.15\%; N, 8.84\%.

Synthesis of 2-[4-(azepan-1-yl) but-2-yn-1-yl]-2,3,3a,4,7,7ahexahydro-1H-isoindole-1,3-dione (AZ-3)

The titled compound was prepared following the general procedure for synthesis of aminoacetylenic compounds 1-6, yielded $2.85 \mathrm{~g}$ 95\%. IR: 2920 (C-H stretch), 2825 (Ar C-H stretch), 1702 (Ar C=C stretch), 1190 (Alk N-C stretch). ${ }^{1} \mathrm{H}-\mathrm{NMR}$ (DMSO-d 6 ): $\delta, 5.82$ (s, 2H, $\mathrm{ArH}), 4.11\left(\mathrm{~s}, \mathrm{H}, \mathrm{C}-\mathrm{CH}_{2}-\mathrm{N}\right), 3.63\left(\mathrm{~s}, \mathrm{H}, \mathrm{CH}_{2}-\mathrm{C}\right), 1.51$ (m, various protons of cyclic amine). Anal. Calcd, $\left(\mathrm{C}_{18} \mathrm{H}_{24} \mathrm{~N}_{2} \mathrm{O}_{2}\right)$ : C, $72.09 \%$; $\mathrm{H}$, 8.00\%; N, 9.33\%. Found: C, 71.96; H, 8.02\%; N, 9.30\%.

Synthesis of 2-[4-(piperdin-1-yl)but-2-yn-1-yl]-2,3,3a,4,7,7ahexahydro-1H-isoindole-1,3-dione (AZ-4)

The titled compound was prepared following the general procedure for synthesis of aminoacetylenic compounds $1-6$, yielded $2.7 \mathrm{~g}$ 94.4\%. IR: 2938 (C-H stretch), 2843 (Ar C-H stretch), 1690 (Ar C=C stretch), 1250 (Ar N-C stretch), 875 (Ar C-H bend). ${ }^{1} \mathrm{H}-\mathrm{NMR}$ (DMSO$\left.\mathrm{d}_{6}\right): \delta, 5.64(\mathrm{~s}, 2 \mathrm{H}, \mathrm{ArH}), 4.05\left(\mathrm{~s}, \mathrm{H}, \mathrm{C}-\mathrm{CH}_{2}-\mathrm{C}\right), 1.92,2.14(\mathrm{~d}$, various protons of cyclic amine). Anal. Calcd, $\left(\mathrm{C}_{17} \mathrm{H}_{22} \mathrm{~N}_{2} \mathrm{O}_{2}\right)$ : C, 68.6\%; $\mathrm{H}$, $6.07 \%$; N, 8.07\%. Found: C, 68.45\%; H, 6.2\%; N, 8.1\%.

Synthesis of 2-[4-(4-methylpiperazin-1-yl)but-2-yn-1-yl]-2,3,3a, 4,7,7a-hexahydro-1H-isoindole-1,3-dione (AZ-5)

The titled compound was prepared following the general procedure for synthesis of aminoacetylenic compounds 1-6, yielded $2.9 \mathrm{~g}$ 96.34\%. IR: 2.947 (C-H stretch), 2832 (Ar C-H stretch), 1707 (Ar C=C stretch). ${ }^{1} \mathrm{H}-\mathrm{NMR}$ (DMSO-d 6 ): $\delta, 5.88(\mathrm{~d}, 2 \mathrm{H}, \mathrm{ArH}), 4.12\left(\mathrm{~s}, \mathrm{H}, \mathrm{C}-\mathrm{CH}_{2}-\right.$ $\mathrm{N}), 3.63\left(\mathrm{~s}, \mathrm{H}, \mathrm{CH}_{2}-\mathrm{C}\right), 2.12,2.5$ (m, various protons of cyclic amine). Anal. Calcd, $\left(\mathrm{C}_{17} \mathrm{H}_{22} \mathrm{~N}_{2} \mathrm{O}_{2}\right)$ : C, 68.6\%; H, 6.07\%; N, 8.07\%. Found: C, 68.45\%; H, 6.17\%; N, 8.22\%.

Synthesis of 2-[4-(4-pyrrolidin-1-yl)but-2-yn-1-yl]-2,3,3a,4,7, 7a-hexahydro-1H-isoindole-1,3-dione (AZ-6)

The titled compound was prepared following the general procedure for synthesis of aminoacetylenic compounds 1-6, yielded $2.6 \mathrm{~g}$ 95.58\%. IR: 2.936 (C-H stretch), 2840 (Ar C-H stretch), 1720 (Ar C=C stretch), 1253 (Ar N-C stretch), 870 (Ar C-H bend). ${ }^{1} \mathrm{H}-\mathrm{NMR}$ (DMSO$\left.\mathrm{d}_{6}\right): \delta, 5.85(\mathrm{~s}, 2 \mathrm{H}, \mathrm{ArH}), 4.11\left(\mathrm{~s}, \mathrm{H}, \mathrm{C}-\mathrm{CH}_{2}-\mathrm{C}\right), 3.56\left(\mathrm{~s}, \mathrm{H}, \mathrm{CH}_{2}-\mathrm{C}\right), 2.16$ (m, various protons of cyclic amine). Anal. Calcd, $\left(\mathrm{C}_{16} \mathrm{H}_{20} \mathrm{~N}_{2} \mathrm{O}_{2}\right)$ : C, 71.64\%; H, 2.46\%; N, 8.90\%. Found: C, 71.40\%; H, 2.43\%; N, 8.82\%.

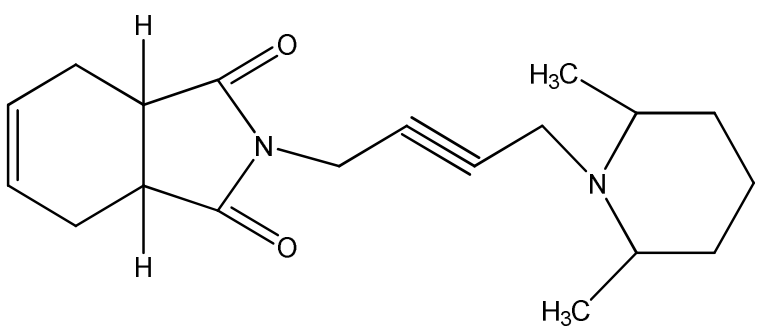

Fig. 1: 2-[4-(2,6-dimethylpiperidin-1-yl)but-2-yn-1-yl]2,3,3a,4,7,7a-hexahydro-1H-isoindole-1,3-dione. (AZ-2)

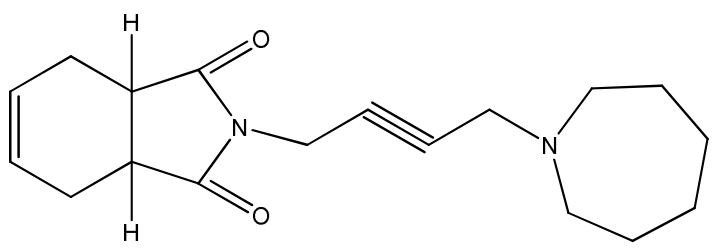

Fig. 2: 2-[4-(azepan-1-yl) but-2-yn-1-yl]-2,3,3a,4,7,7ahexahydro-1H-isoindole-1,3-dione. (AZ-3)

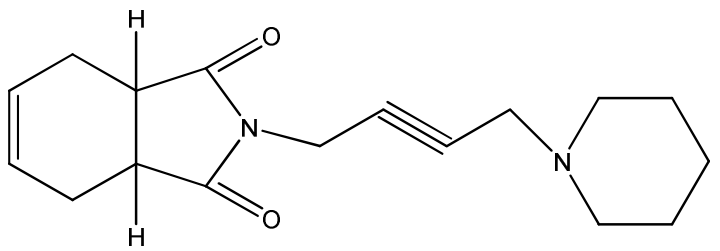

Fig. 3: 2-[4-(piperidine-1-yl)but-2-yn-1-yl]-2,3,3a,4,7,7ahexahydro-1H-isoindole-1,3-dione. (AZ-4)

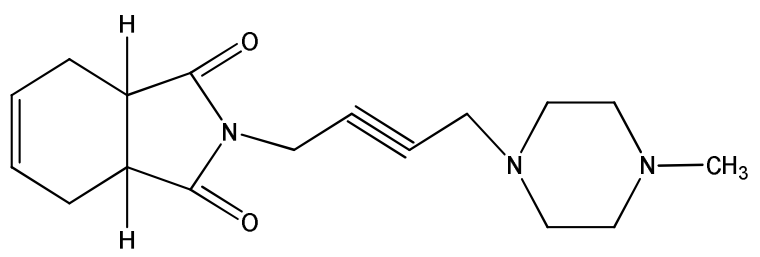

Fig. 4: 2-[4-(4-methylpiperazine-1-yl)but-2-yn-1-yl]2,3,3a,4,7,7a-hexahydro-1H-isoindole-1,3-dione. (AZ-5)

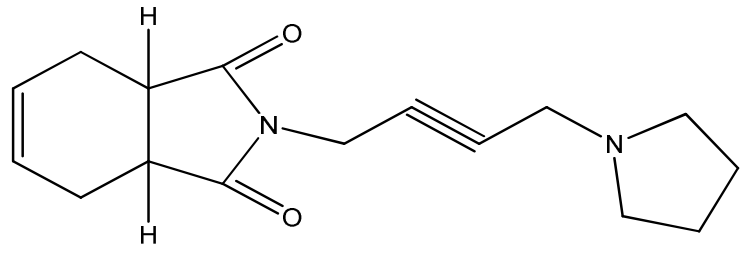

Fig. 5: 2-[4-(4-pyrrolidine-1-yl) but-2-yn-1-yl]-2,3,3a,4,7,7ahexahydro-1H-isoindole-1,3-dione. (AZ-6)

\section{B-Molecular docking studies for AZ 1-6}

The 3D structures of COX-1 and COX-2 enzymes were downloaded from the protein data bank [12] (PDB, ID: 3N8Z [13, 14] and 3NTI [11]) and then all water molecules were removed. Partial charges were assigned to all atoms using Kollman united atom model that 
exists in the Autodock Tool software [15, 16, 17]. Preparations of the COX- 1 and COX- 2 active site were completed by creating a grid box of a 50 x $50 \AA$ size with a grid spacing of $0.375 \AA$ using Autogrid (part of the Autodock software package $[18,19]$ ). The active site was identified using the COX-1 and COX-2 co-crystallized ligands. After preparing the protein structure, the ligand preparation process was initiated by building their own 3D structures using the Maestro software [20]. A minimization process was carried out on each ligand structure using OPLS force field [21]. Subsequently, Gasteiger-Marsili model [22] was employed to assign partial charges for all prepared ligands. Tertiary amines of all ligands were set as protonated. The ligands were separately docked into the previously prepared active site using Autodock [18, 19] (version 4.2). Whereas the protein structure was treated as a rigid entity, the ligand structures were treated as flexible, and a conformational sampling process was carried out using Lamarckian Genetic Algorithm [18]. The Autodock scoring function was then used to score all docked poses. The Autodock scoring function includes different terms for van der Waals, hydrogen bond, electrostatic interactions, and the ligand internal energy. AZ-5 has two tertiary amine groups in the piperazine ring where one of them is expected to be protonated at physiological $\mathrm{pH}$. Thus, two forms of AZ-5 were built with one of the tertiary amine groups is protonated and everyone was then docked separately in the COX active site.

\section{C-In vitro cyclooxygenase enzyme assays for AZ1-6}

The activity of the synthesised compounds (AZ1-6) on ovine COX-1 and human recombinant COX-2 was determined using COX Inhibitor Screening Kit from Cayman Chemical Company (Ann Arbor, MI) following manufacturer's instructions. In brief, this assay measures PGF2 $\alpha$ produced by stannous chloride $\left(\mathrm{SnCl}_{2}\right)$ reduction of COXderived PGH2. The target compounds were dissolved in DMSO to provide three stock solution. After which, $10 \mu \mathrm{l}$ of each stock solution was added to $160 \mu \mathrm{l}$ of reaction buffer solution $(0.1 \mathrm{M}$ TrisHCL, pH-8 containing $5 \mathrm{~mm}$ EDTA and $2 \mathrm{~mm}$ phenol), $10 \mu \mathrm{l}$ of either COX-1 or COX-2 enzymes and $10 \mu \mathrm{l}$ of heme. These solutions were incubated for $10 \mathrm{~min}$ at $37^{\circ} \mathrm{C}$. Followed by the addition of $10 \mu \mathrm{l}$ arachidonic Acid solution and then incubate for $2 \mathrm{~min}$ at $37^{\circ} \mathrm{C}$ to initiate the reaction. After which, $30 \mu \mathrm{l}$ of the $\mathrm{SnCl}_{2}$ solution was added to stop COX reaction by reducing PGH2 to PGF2 $\alpha$. The prostanoid product was then quantified via enzyme immunoassay using specific PG antiserum. This immunoassay was based on the competition between PGs and PG-acetyl cholinesterase (PG-AChE) conjugation (PG tracer) on the limited amount of PG antiserum bound to mouse anti-rabbit monoclonal antibodies previously attached to the well. Since the concentration of PGs tracer is held constant while the concentration of PGs varies, the amount of PG tracer that is able to bind to the PG antiserum was inversely proportional to the concentration of PGs in the well. The plate was then washed to remove any unbound reagents and then Elliman's reagent, which contains AChE substrate was added to the well. The product of this enzymatic reaction produces a distinct yellow colour which was measured spectrophotometrically (Microtiter Plate reader) at $412 \mathrm{~nm}$. The colour intensity was proportional to the amount of PG tracer bound, which was inversely proportional to the amount of PGs present in the well during the incubation

\section{Absorbance $\alpha$ [Bound PG tracer] $\alpha$ 1/PGs \\ RESULTS AND DISCUSSION}

\section{Chemistry}

The designed compounds were prepared as shown in schemes 1 and 2. Scheme 1 involved the alkylation of tetrahydro phthalimide with 3bromo prop-1-yne (propargyl bromide) in the presence of acetonitrile as a solvent under basic conditions. The reaction involves direct displacement of the anionic nitrogen of tetrahydro phthalimide on the propargyl bromide to generate 2-(prop-2-yn-1-yl)-2,3,3a,4,7,7ahexahydro-1H-isoindole-1,3-dione. Compound AZ-1 was generated via nucleophilic displacement of bromide located at 3-bromoprop-1-yne. The Mannich reaction of 2-(prop-2-yn-1-yl)-2,3,3a,4,7,7a-hexahydro1H-isoindole-1,3-dione (AZ-1) with formaldehyde, appropriate cyclic amine and a catalytic amount of cuprous chloride in peroxide-free 1,4dioxane was heated to $80^{\circ} \mathrm{C}$ to yield the designed compounds (AZ2-6). The yield obtained ranged from $52.4-60.75 \%$.

The proposed mechanism for Mannich reaction is shown in scheme 2, in order for Mannich reaction to proceed, a reactive immonium cations intermediates should be formed from the condensation of the formaldehyde and the appropriate amine (Schiff base formation). The attack of the carbanion in 2-(prop-2-yn-1-yl)-2,3,3a,4,7,7a-hexahydro$1 \mathrm{H}$-isoindole-1,3-dione-benzothiazole cuprous salt on the Schiff base generates the desired Mannich products (AZ2-6). The structures were verified by IR, ${ }^{1} \mathrm{H}-\mathrm{NMR},{ }^{13} \mathrm{C}$-NMR and elemental analysis, and were consistent with the assigned structures.

The designed compounds were prepared according to scheme 1 .

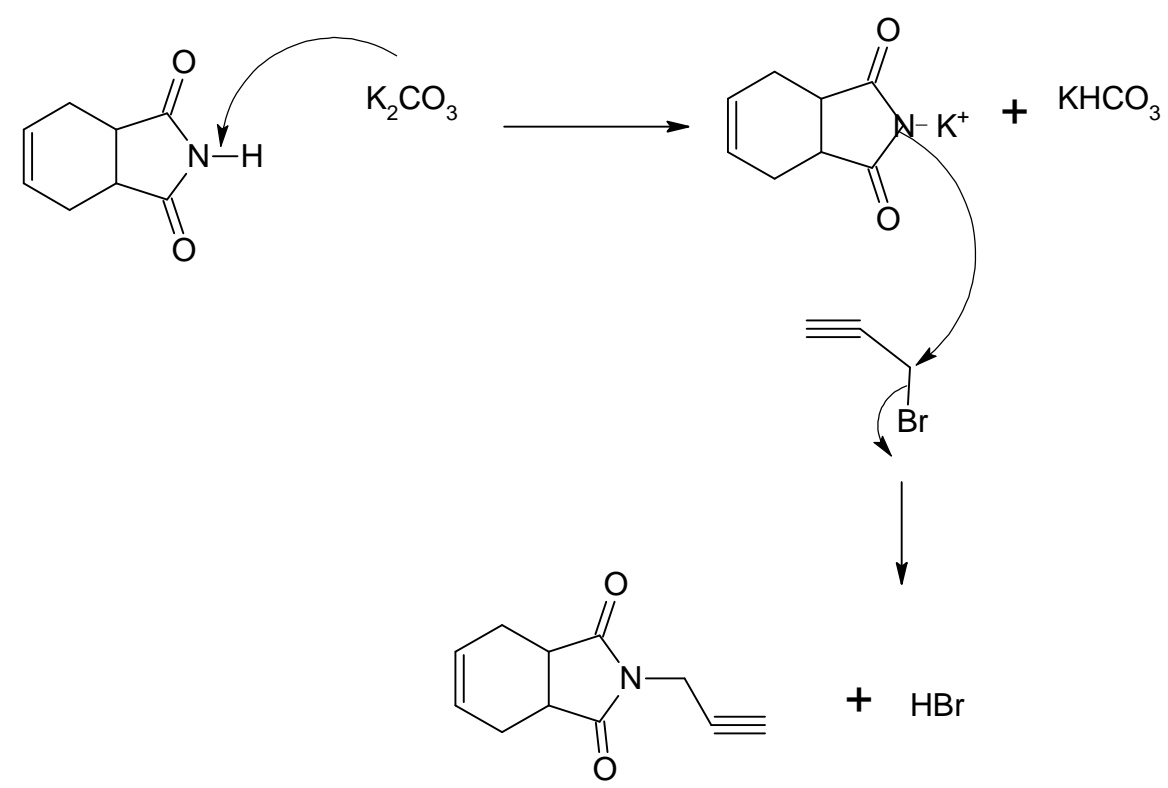

2-(prop-2-yn-1-yl)-1H-isoindole-1,3(2H)-dione

Scheme 1: Alkylation reaction of tetrahydro phthalimide moiety 
The proposed mechanism for Mannich reaction is outlined in scheme 2
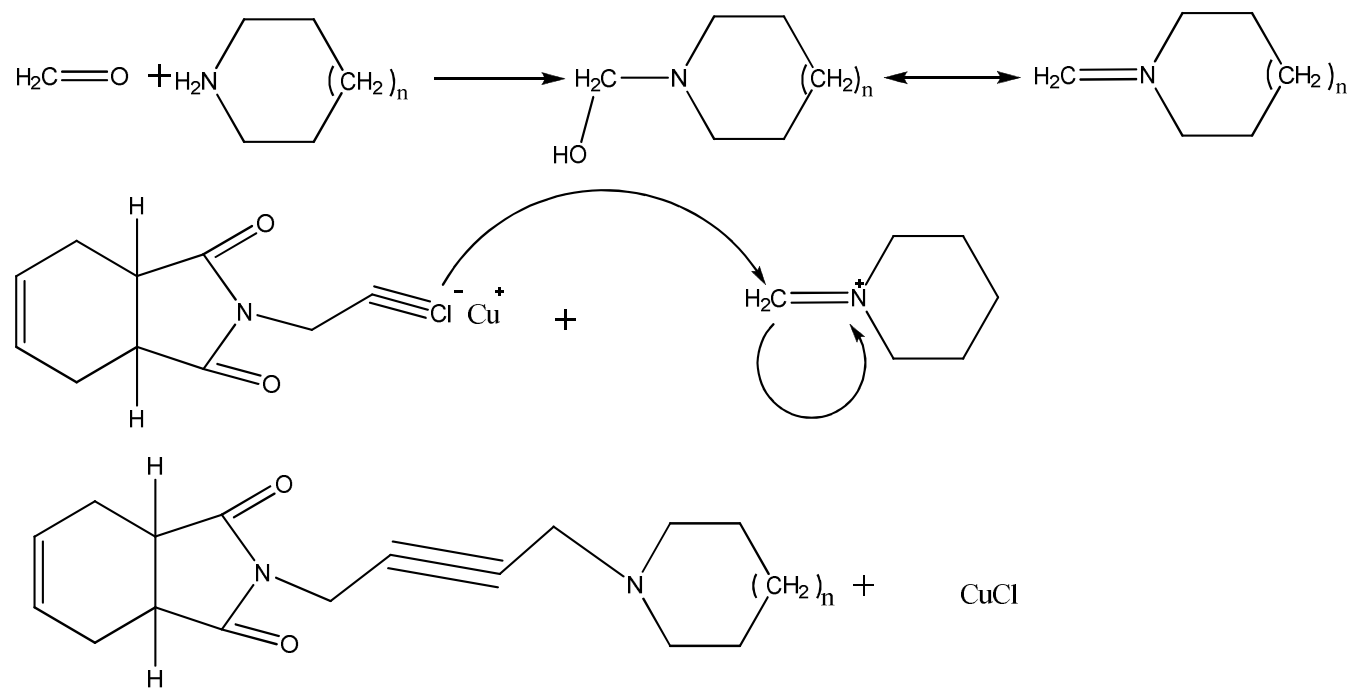

Scheme 2: Proposed mannich reaction

\section{Molecular modeling}

In the present study, to understand the interaction between the ligands of the synthesised compounds (AZ1-6) and COXs and to explore their binding mode, docking study was performed using Autodock Tool software [23]. The synthesised compounds were investigated for their docking binding with COXs structures and their ability to inhibit COX activity as reflected in the removal of the double bond in this hexahydro-1H-isoindole-1,3-dione. According to Duggan and his co-workers [11], NSAIDs bind to two key groups of amino acids in the COX-1 and COX-2 active site, Ser530 and Tyr385 in the top of the catalytic pocket or Arg120 and Tyr355 in the bottom of the pocket. For instance, diclofenac binds to the first group residues (top) and flurbiprofen interacts to the latter group residues (bottom), mainly via electrostatic interactions that are made between polar heads of such residues and the carboxylate group in these NSAIDs structures. The NSAIDs hydrophobic groups also have a role in the binding via making van der Waals interactions with the hydrophobic residues lining the active pocket [11].

Binding energies of the best-docked pose of all six compounds are shown in table 1 , along with the flurbiprofen and celecoxib scoring as a reference. All compounds were seemed to fit well in the COX-1 as well as in the COX-2 active sites (they have favourable binding energies). Interestingly, AZ-6 had shown a remarkable binding energy $(-8.6 \mathrm{kcal} / \mathrm{mol})$ in the COX-1 active site, which was very close to the diclofenac's binding energy $(-8.7 \mathrm{kcal} / \mathrm{mol})$. As shown in fig. 2 . A, AZ-6 also possessed a similar binding mode as diclofenac where the best pose was seemed to fit in the COX-1 catalytic pocket pleasantly and to make the same hydrogen bonding interactions that were made by diclofenac. These interactions were made by ligand protonated amino group and a cyclic carbonyl group. Obviously, these interactions were assisted by the existence of the acetylenic group which acted as an anchor; via placing these two polar groups in the correct position for binding. In addition to these electrostatic interactions, extensive hydrophobic interactions were made between the ligand carbon atoms and the side chains of Tyr348, Val349, Le352, Phe381, Leu384, Trp387, and Leu534. Although AZ-6 obtained a very good score in the COX-2 active site. AZ-4 seemed to have the best affinity towards the enzyme active site. Fig. 2. B shows how AZ-4 nicely fitted in the COX-2 pocket, making many van der Waal contacts with the surrounding hydrophobic residues. In terms of electrostatics, interestingly, two unusual and strong hydrogen bonding interactions were made between the protonated nitrogen and the backbone amide of Leu352 and Ser353, and another weak hydrogen bond was made between the cyclic carbonyl group and the Ser530 side chain at the top of the catalytic pocket. The docking scores data (table 1) indicated a close similarity in the binding affinity to both COXs and may be more selective to COX-1 as in flurbiprofen. Colorimetric COXs (ovine/human) inhibition as shown in table 2 that compound AZ-5 showed the highest \% of inhibition for COX-1 even better than aspirin, while no inhibition for COX-2, but rather stimulation.
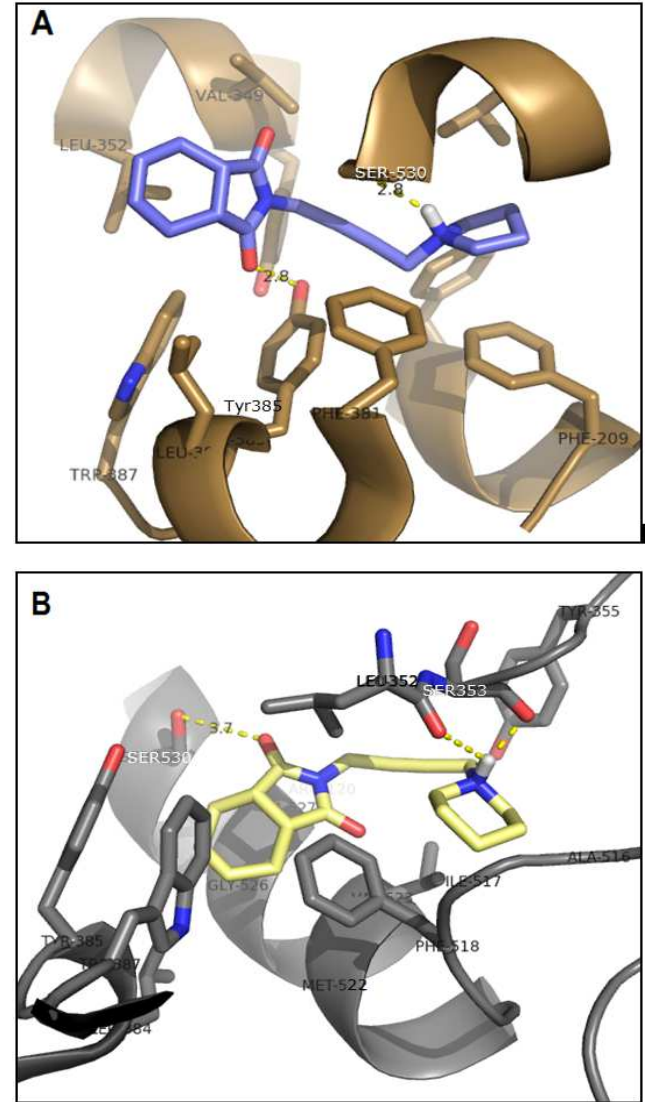

Fig. 6: (A) Shows the binding mode of AZ-6 (blue) within the COX-1 active site (gold). (B) Shows the binding mode AZ-4 (yellow) within the COX-2 active site (gray), respectively. Yellow dotted lines indicate for hydrogen bonding. The picture was generated by PyMol. [12] Some protein chains are not shown for clarity 
It is for the first time in our amino acetylenic compounds as antiinflammatory compounds were their docking results in reverse effect to COXs inhibition. Our rationalisation for this phenomena may be due to the lack of the double bond, loss of aromaticity in hexahydro1h-isoindole-1,3-dione and the lack of overlap with aryl containing an amino acid that is necessary to trigger inhibitory activity.

The results of In vitro cyclooxygenases (COXs) enzyme assays showed some selective COX-1 inhibitory activity in particular compounds AZ-5 which was more potent than aspirin. While all the same design compounds were lacking COX-2 inhibitory activity as illustrated in table 2. In considering the structural differences between amino acetylenic phthalimide derivatives and their corresponding amino acetylenic tetrahydro phthalimide derivatives we recognised the lack of the double bond in our newly design tetrahydro phthalimide derivative, in spite of the rigidity of phthalimide derivatives which was not sufficient for COX-2 inhibitory activity. It seems that the aromaticity is critical for their inhibitory activity.

Table 1: Docking scores (binding affinity) of AZ1-6 compounds, flurbiprofen and celecoxib into COX-1 and COX-2 active site

\begin{tabular}{lll}
\hline Molecule & Autodock scores in COX-1 (kcal/mol) & Autodock scores in COX-2 (kcal/mol) \\
\hline AZ-1 & -7.8 & -7.9 \\
AZ-2 & -7.7 & -8.0 \\
AZ-3 & -7.7 & -8.1 \\
AZ-4 & -7.9 & -8.6 \\
AZ-5 & -7.7 (resonance-1) & -7.9 (resonance-1) \\
& -7.9 (resonance-2) & -7.9 (resonance-2) \\
AZ-6 & -8.5 & -8.4 \\
Flurbiprofen & -8.7 & -8.0 \\
Celecoxib & -8.5 & -10.6 \\
\hline
\end{tabular}

2-(prop-2-yn-1-yl)-2,3,3a,4,7,7a-hexahydro-1H-isoindole-1,3-dione (AZ-0), 2-[4-(2,6-dimethylpiperidine-1-yl)but-2-yn-1-yl]-2,3,3a,4,7,7a-hexahydro1H-isoindole-1,3-dione (AZ-2), 2-[4-(azepan-1-yl)but-2-yn-1-yl]-2,3,3a,4,7,7a-hexahydro-1H-isoindole-1,3-dione (AZ-3), 2-[4-(piperdin-1-yl)but-2yn-1-yl]-2,3,3a,4,7,7a-hexahydro-1H-isoindole-1,3-dione (AZ-4), 2-[4-(4-methylpiperazin-1-yl)but-2-yn-1-yl]-2,3,3a,4,7,7a-hexahydro-1H-isoindole-1,3dione (AZ-5), 2-[4-(4-pyrrolidin-1-yl)but-2-yn-1-yl]-2,3,3a,4,7,7a-hexahydro-1H-isoindole-1,3-dione (AZ-6)

Table 2: Percentage (\%) inhibition of COX-1 and COX-2 with (AZ 1-6) compounds

\begin{tabular}{llll}
\hline Compounds & & \% Inhibition of COX-1 & \% Inhibition of COX-2 \\
\hline AZ-1 & 2-methylpiperidine $100 \mu \mathrm{m}$ & 22 & -4 \\
AZ-1 & 2-methylpiperidine $10 \mu \mathrm{m}$ & 26 & -12 \\
AZ-1 & 2-methylpiperidine $1 \mu \mathrm{m}$ & 10 & -36 \\
AZ-2 & Piperidine $100 \mu \mathrm{m}$ & 22 & -10 \\
AZ-2 & Piperidine $10 \mu \mathrm{m}$ & -25 & -4 \\
ZA-2 & Piperidine $1 \mu \mathrm{m}$ & 15 & -49 \\
AZ-5 & N-methylpiperidine $100 \mu \mathrm{m}$ & -5 & 1 \\
AZ-5 & N-methylpiperidine $10 \mu \mathrm{m}$ & -19 & -1 \\
AZ-5 & N-methylpiperidine $1 \mu \mathrm{m}$ & 64 & -26 \\
AZ-6 & Pyrrolidine $100 \mu \mathrm{m}$ & 9 & -8 \\
AZ-6 & Pyrrolidine $10 \mu \mathrm{m}$ & 1 & -10 \\
AZ-6 & Pyrrolidine $1 \mu \mathrm{m}$ & 19 & -21 \\
Aspirin & Acetylsalicylic acid $100 \mu \mathrm{m}$ & 14 & -21 \\
Aspirin & Acetylsalicylic acid $10 \mu \mathrm{m}$ & -13 & -75 \\
Aspirin & Acetylsalicylic acid $1 \mu \mathrm{m}$ & -11 & -6 \\
\hline
\end{tabular}

\section{In vitro evaluation}

The inhibitory activity of the synthesised compounds (AZ 1-6) on COX1 and COX-2 was determined, and the results are listed in table 2.

\section{CONCLUSION}

To the best of our knowledge, for the first time to find Aryl group that could selectively differentiate between COX-1 and COX-2 inhibitory activity.

\section{FUNDING}

This research did not receive any specific grant from funding agencies in the public, commercial, or not-for-profit sectors.

\section{ACKNOWLEDGMENT}

The authors would like to thank the University of Petra/Faculty of Pharmacy, for providing the necessary facilities to carry out this work.

\section{CONFLICT OF INTERESTS}

The authors have declared no conflict of interest.

\section{REFERENCES}

1. Bhati SK, Kumar AS. Synthesis of new substituted azetidinyol and thiazolidinoyl-1,3,4-thiadiazino(6,5-b) indoles as promising antiinflammatory agents. Eur J Med Chem 2008;43:2323-30.
2. Lombardino G. Non-Steroidal Antiinflammatory drugs. $1^{\text {st }}$ ed John Wiley and Sons, New York; 1985.

3. Dannhardi G, Kiefer W. Cyclooxygenase inhibitors-current status and future prospects. Eur J Med Chem 2001;36:109-26.

4. Carter JS. Inhibition of cyclooxygenase-2. Expert Opin Ther Pat 2000;10:1011-20.

5. Farooqui M, Bora R, Patil CR. Synthesis, analgesic and antiinflammatory activities of novel 3-(4-acetamido-benzyl)-5substituted-1,2,4-oxadiazoles. Eur J Med Chem 2009;44:794-9.

6. Xie W, Chipman JG, Robertson DL, Erikson RL, Simmons DL. Expression of a mitogen-responsive gene encoding prostaglandin synthase is regulated by mRNA splicing. Proc Natl Acad Sci USA 1991;88:2692-6.

7. Ranatunge RR, Garvey DS, Janero DR, Letts LG, Martino AM, Murty MG, et al. Synthesis and selective cyclooxygenase-2 (COX-2) inhibitory activity of a series of novel bicyclic pyrazoles. Bioorg Med Chem 2004;12:1357-66.

8. Orjales A, Mosquera R, Lopez B, Olivera R, Labeaga L, Nunez MT. Novel 2-(4-methylsulfonylphenyl) pyrimidine derivatives as highly potent and specific COX-2 inhibitors. Bioorg Med Chem 2008;16:2183-99.

9. Reddy MV, Billa VK, Pallela VR, Mallireddigar MR, Boominathan R, Gabriel JL, et al. Design, synthesis and biological evaluation of 1-(4sulfamylphenyl)-3-trifluoromethyl-5-indolylpyrazolines as cyclooxygenase-2 (COX2) and lipoxygenase (LOX) inhibitors. Bioorg Med Chem 2008;16:3907-16. 
10. Al-Qaisi JA, Alhussain TM, Qinna NA, Matalka KZ, Al-Kaissi EN, Muhi-eldeen ZA. Synthesis and pharmacological evaluation of amino acetylenic isoindoline-1,3-dione derivatives as antiinflammatory agents. Arab J Chem 2014;7:1024-30.

11. Duggan KC, Walters MJ, Musee J, Harp JM, Kiefer JR, Oates JA, et al. Molecular basis for cyclooxygenase inhibition by the nonsteroidal anti-inflammatory drug naproxen. J Biol Chem 2010;285:34950-9.

12. RCSB Protein Data Bank. Available from: http://www.pdb.org/. [Last accessed on 02 Sep 2016].

13. Sidhu RS, Lee JY, Yuan C, Smith WL. Comparison of cyclooxygenase-1 crystal structures; cross-talk between monomers comprising cyclooxygenase-1 homodimers. Biochemistry 2010;49:7069-79.

14. Devi SK, Velmurugan D. Molecular modelling, Quantitative structureactivity relationship and pharmacophore studies on antiviral, antimalarial and anti-inflammatory bioactive compounds from marine sources. Asian J Pharm Clin Res 2015;8:36-43.

15. Sanner MF. Python: a programming language for software integration and development. J Mol Graph Model 1999;17:57-61.

16. Weiner SJ, Kollman PA, Case DA, Singh UC, Ghio C, Alagona G. A new force field for the molecular mechanical simulation of nucleic acids and proteins. J Am Chem Soc 1984;106:765-84.

17. Jayaprakash R, Saroj Kumar SHA, Hemalatha S, Easwaramoorthy D. Synthesis, characterization, quantitative structure-activity relationship, docking, antibacterial activity, and brine shrimp lethal, studies on L-phenylalanine Schiff bases. Asian J Pharm Clin Res 2016;9:1-6.
18. Morris GM, Goodsell DS, Holliday RS, Huey R, Hart WE, Belew RK. Automated docking using a Lamarckian genetic algorithm and empirical binding free energy function. J Comput Chem 1998;19:1639-62.

19. Morris GM, Huey R, Lindstrom WF, Sanner MF, Belew RK, Goodsell DS. AutoDock4 and AutoDockTool4: automated docking with selective receptor flexibility. J Comput Chem 2009;30:2785-91.

20. Maestro, version 9.2, Schrödinger, LLC, New York, NY; 2011.

21. Jorgensen WL, Tirado-Rives J. The OPLS (optimised potentials for liquid simulations) potential functions for proteins, energy minimization for crystals of cyclic peptides and crambin. J Am Chem Soc 1988;110:1657-66.

22. Gasteiger J, Marssili M. Iterative partial equalization of orbital electronegativity-a rapid access to atomic charge. Tetrahedron 1980;36:3219-28.

23. Muthukala B, Sivakumari $\mathrm{K}$, Ashok $\mathrm{K}$, In silico docking of quercetin compound against the Hela cell line protein. Int J Chem Pharm Res 2015;7:13-6.

\section{How to cite this article}

- Ahmed Basim, Zuhair A Muhi-Eldeen, Elham N AL-Kaissi, Ghadeer Suaifan, Mohammad A Ghattas, Tawfeeq Arafat, Ibrahim S AL-Adham. Design, synthesis and biological screening of amino acetylenic tetrahydro phthalimide analogues as novel cyclooxygenase (cox) inhibitors. Int J Pharm Pharm Sci 2017;9(2):160-165. 